\title{
Detection of Toxoplasma gondii in cat's internal organs by immunohistochemistry methods labeled with-[strept] avidin-biotin
}

\author{
Muhammad Hanafiah ${ }^{1}$, Raden Wisnu Nurcahyo², Rika Yuniar Siregar ${ }^{3}$, Joko Prastowo ${ }^{2}$, Sri Hartati ${ }^{4}$, Bambang Sutrisno ${ }^{5}$ \\ and Dwinna Aliza6
}

1. Parasitology Laboratory, Faculty of Veterinary Medicine, Syiah Kuala University, Banda Aceh, Indonesia; 2. Department of Parasitology, Faculty of Veterinary Medicine, Gadjah Mada University, Yogyakarta, Indonesia; 3. Veterinary Public Health of Laboratory, Diseases Investigation Center, Wates, Yogyakarta, Indonesia; 4. Department of Clinic, Faculty of Veterinary Medicine, Gadjah Mada University, Yogyakarta, Indonesia; 5. Department of Pathology, FKH UGM, Sekip Unit II Yogyakarta 55281, Yogyakarta, Indonesia; 6. Pathology Laboratory, Faculty of Veterinary Medicine, Syiah Kuala University Banda Aceh, Indonesia.

Corresponding author: Muhammad Hanafiah, e-mail: hanafi_2015@unsyiah.ac.id

Co-authors: RWN: wisnu-nc@ugm.ac.id, RYS: rysiregar@yahoo.com,.JP: joko2456@yahoo.com,

SH: toxocat1001@yahoo.com, BS: bambangsutrisno@ugm.ac.id, DA: dwinna2000@yahoo.com

Received: 22-03-2017, Accepted: 03-08-2017, Published online: 06-09-2017

doi: 10.14202/vetworld.2017.1035-1039 How to cite this article: Hanafiah M, Nurcahyo RW, Siregar RY, Prastowo J, Hartati S, Sutrisno B, Aliza D (2017) Detection of Toxoplasma gondii in cat's internal organs by immunohistochemistry methods labeled with-[strept] avidin-biotin, Veterinary World, 10(9): 1035-1039.

\begin{abstract}
Aim: The aims of the study are to detect the presence of Toxoplasma gondii antigen and to determine its distribution location in several organs of domestic cat using immunohistochemistry (IHC) method with Labeled-[Strept] Avidin-Biotin (LAB-SA).

Material and Methods: Four domestic cats aged 1-2 years were used as sample in this research. The sample divided into two groups with two cats each. Cats in Group I were positive Toxoplasma based on serologically screening test, while cats in Group II were orally infected with $1 \times 10^{6}$ Toxoplasma oocyst. All samples then necropsied, and the organs including brain, liver, kidney, duodenum, jejunum, ileum, lungs, and spleen were collected for IHC method with LAB-SA.

Result: The result showed that Toxoplasma antigens were detected in ileum of both serologically positive domestic cat and the experimentally infected cats. Toxoplasma was also observed in kidney of serologically positive domestic cat. In the serologically positive domestic cat, necrotic lesions were found on ileum, kidney, and liver, whereas in experimentally infected cat, the lesion was only found on ileum.
\end{abstract}

Conclusion: The presence of Toxoplasma antigen is successfully detected in several organs of domestic cat using IHC method with the LAB-SA.

Keywords: cat, immunohistochemistry, labeled-[strept] avidin-biotin, Toxoplasma gondii.

\section{Introduction}

The obligate intracellular parasite Toxoplasma gondii infects a broad range of mammalian and avian hosts including approximately one-third of the human population [1-4].

Toxoplasmosis is a globally spread zoonosis with a clinical impact on the unborn fetuses and the immunosuppressed individuals, furthermore, it is regarded as one of the leading causes of death in food-borne illness [5]. Toxoplasmosis is a worldwide reported zoonotic infection caused by the protozoon Toxoplasma gondii [6]. T. gondii cause a lifelong chronic infection in host by impede and suppress the immune system $[7,8]$.

The domestic and other felids have been proven as the major reservoir host of $T$. gondii infection.

Copyright: Hanafiah, et al. Open Access. This article is distributed under the terms of the Creative Commons Attribution 4.0 International License (http://creativecommons.org/licenses/ by/4.0/), which permits unrestricted use, distribution, and reproduction in any medium, provided you give appropriate credit to the original author(s) and the source, provide a link to the Creative Commons license, and indicate if changes were made. The Creative Commons Public Domain Dedication waiver (http:// creativecommons.org/publicdomain/zero/1.0/) applies to the data made available in this article, unless otherwise stated.
It is generally assumed that cats play a major role in transmitting $T$. gondii through fecal contamination of soil, food, and water because they can excrete millions of oocysts in short period of time (1-2 weeks) [9]. The infection can be obtained by eating raw or undercooked meat containing cysts or consuming food or water contained with sporulated oocysts $[10,11]$ or by ingestion of raw milk and milk products [12].

Several laboratory methods have been developed to detect antibody in serum of infected cat such as polymerase chain reaction, enzyme-linked immunosorbent assay, latex agglutination test, indirect hemagglutination test, indirect fluorescent antibody test, and immunochromatography (IC). Although these tests are expensive and require a specialized laboratory, they are more sensitive and specific $[13,14]$.

IC is a rapid, simple, sensitive, and specific diagnostic tool to detect specific antibodies from $T$. gondii infection in cats in field conditions [15]. Fecal flotation technique is used to detect oocyst in fecal samples as well. Although flotations are a reference method for the detection of $T$. gondii oocysts, it has been suggested than an alternative test is also needed due to 
the microscopic examination is time-consuming and needs an experience microscopist [16].

The study of detecting parasites within host organs could not be conducted easily. To overcome the limitation of conventional methods, new diagnostic methods are devised, such as histopathology and immunochemistry method $[17,18]$. The most widely used and highly sensitive immunohistochemistry (IHC) method is avidin-biotin method or commonly called avidin-biotin complex (ABC) [19].

The most commonly used avidin-biotin method is labeled avidin-biotin (LAB) or labeled streptavidin avidin-biotin (LSAB) with biotinylated secondary antibody and three reagents from peroxide or alkaline phosphate. This method has higher sensitivity compared to other ABC methods [20].

The purpose of this study is to detect the appearance of $T$. gondii antigen and to determine its distribution location in several organs of domestic cat using IHC method with labeled-(Strept) avidin-biotin (LAB-SA).

\section{Materials and Methods}

Ethical approval

The study was approved by the Ethics Committee of Ethical Clearance for Pre-clinical Research, Integrated Research and Testing Laboratory, Gadjah Mada University, Yogyakarta, Indonesia (approval no. 00111/09).

\section{Sample preparation}

Four domestic cats aged 1-2 years were used as sample in this research. The sample divided into two groups with two cats each. Cats in Group I were positive Toxoplasma based on serologically screening test (tested by Feline Anigen Toxoplasma Ab Rapid Test Kit), while cats in Group II were orally infected with $1 \times 10^{6}$ Toxoplasma oocyst. The cats were euthanized using an intravenous injection of $20 \%$ pentobarbitone solution as a euthanized material which highly recommended by World Society for the Protection of Animals, London. This method is considered best practice because it consistently produces a death when used as the sole means of euthanasia. Then, a necropsy was performed on both individuals, followed by the collections of the organs including brain, liver, kidney, duodenum, jejunum, ileum, lungs, and spleen for IHC method with LAB-SA (Invitrogen ${ }^{\mathrm{TM}}$ ) process.

\section{IHC}

The LAB-SA test was performed according to the manufacturer instruction (Invitrogen Inc., USA). After deparaffinization, the endogenous peroxidase activity of each tissue was blocked with $0.3 \% \mathrm{H}_{2} \mathrm{O}$. The IHC slides were stained by histostain ${ }^{\circledR}$ (Invitrogen, USA). Four micrometers thick placentome sections were cut from the zinc salt fixed blocks, mounted on positively charged glass slides (Superfrost ${ }^{\mathbb{B} P l u s, ~ G e r m a n y) ~ a n d ~}$ air-dried before incubation at $57^{\circ} \mathrm{C}$ for $1 \mathrm{~h}$. Dewaxing and IHC labeling were then carried out on a Ventana ${ }^{\circledR}$
Benchmark XT (Syntec Scientific Ltd., Ireland) automated IHC staining machine. Slides were incubated with primary polyclonal anti- $T$. gondii antibody (rabbit) primary antibody (Abcam, USA) diluted 1/100 at $37^{\circ} \mathrm{C}$ for $32 \mathrm{~min}$ and biotinylated secondary antibody (Abcam, USA). The primary antibody epitope binding was visualized using the DAB CHROMOGEN (Invitrogen, USA). The sections were counterstained with Mayer hematoxylin and bluing reagent (Invitrogen ${ }^{\circledR}$ LAB-SA Detection System). Citrate buffer $(\mathrm{pH}$ 6.0) was used for antigen retrieval and also other reagents from a streptavidin avidin-biotin (LAB-SA) immunoenzymatic antigen.

On completion of staining, slide was raised in a mild detergent solution, and the stained sections were dehydrated through staged alcohols to xylene and coverslipped. Sections were then examined for the presence of positively staining structure consistent with the morphology $T$. gondii. The result interpretation was observed using microscope; positive result showed dark brown tissues (the sample contained antigen), and the negative result showed blue (the sample does not contain the antigen).

\section{Statistical analysis}

The data of antigen Toxoplasma examination on cats, both serologically positive and infected toxoplasmosis on organs using IHC were analyzed descriptively.

\section{Results}

IHC

Results of the examination of several organs by IHC staining are shown in Figure-1a and b:

Macrophages are observed in some organs such as liver, lungs, and kidney of cats which serologically positive Toxoplasmosis. Thus, indicating chronically infected. The result than supported by enzyme-linked fluorescent assay (ELFA) examination which positively reacted to immunoglobulin (Ig) G (Immunoserology IgM anti-Toxoplasma: Reactive: $8.8 \mathrm{IU} / \mathrm{ml})$. Meanwhile, in cats infected with Toxoplasma, macrophages are only found in ileum. This result indicates that the infection is in an

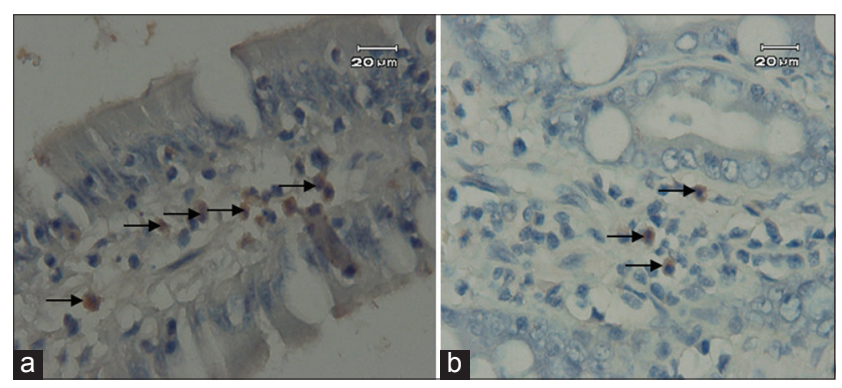

Figure-1: Cat intestine with Toxoplasma positive immunohistochemistry staining. (a) Macrophages in ileum that serologically positive of Toxoplasma (scale bar $=20 \mu \mathrm{m}$ ) (arrow); (b) macrophages in the ileum in cats with an experimentally infected cat of Toxoplasma. (Scale bar $=20 \mu \mathrm{m})$ (arrow). 
acute stage. ELFA examination to strengthened the result was then carried out which showed the positive reactions of all serum to IgM (Immunoserology IgM anti-Toxoplasma: Reactive: 0.71 index).

Some clinical symptoms data have been collected from the examination of body temperature, breath, and pulse frequencies. The clinical symptoms in both serologically positive and experimentally infected cat with toxoplasmosis are included increased breathing (ranging between $20-80 / \mathrm{min}$ and $41-120 / \mathrm{min}$, respectively) and increased heart beat frequency (81-110 and 110-170 bpm, respectively). The results showed that all samples still in normal standard of healthy cat. However, the clinical data were not specific enough to diagnose cat with toxoplasmosis.

\section{Discussion}

The IHC examination results on several organs of experimentally infected cat show that the only part of the small intestine which showed positive result was the ileum (Figure-1a and b), whereas on the other organs were not found. Immunohistochemistry positive result in serologically Toxoplasma positive cat was found intracytoplasmic of epithelial cell of kidney tubules (Figure-2b) and ileum, while on the negative control were not revealed (Figure-2a). Positive reaction was shown by dark brown color, which indicated antigen-antibody binding. The positive reaction in the ileum of both groups existed inside the macrophages.

IHC positive results in this study show a dark brown color. Broad spectrum with diaminobenzidine (DAB) chromogen produces dark brown color on the binding of antigen-antibody Toxoplasma on stained tissue. According to Bionisch [19], DAB would block all the residual primary antibodies from the first immune reactions.

Streptavidin biotin (SB) method is faster, sensitive, and clean with strong color intensity, besides there are no color disruptions by the poor quality of the background. The SB method is 4-8 times more sensitive compare to avidin-biotin method, and 8-16 times more sensitive, and accurate than Papanicolaou (PAP) method. In addition, LAB-SA provides superior sensitivity to that of the avidin-biotin complex $(\mathrm{ABC})[3,4,7,9]$. The LAB-SA method is also sensitive than peroxidase (PAP) methods $[3,7]$ and has
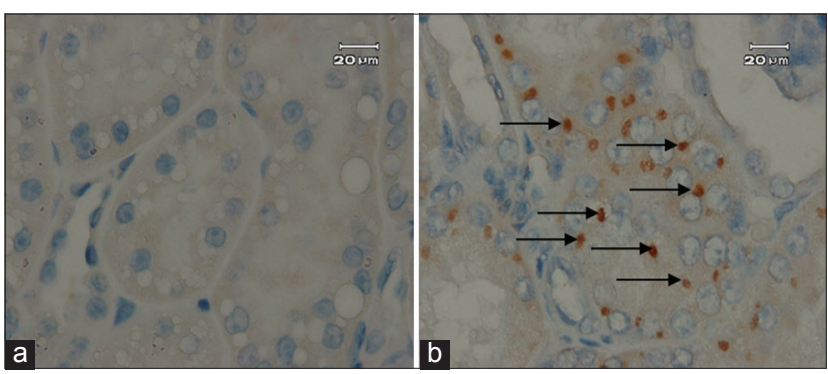

Figure-2: Cat kidney with Toxoplasma positive immunohistochemistry staining. (a) Negative control of immunohistochemistry staining; (b) macrophages in intracytoplasmic tubulus. (scale bar $=20 \mu \mathrm{m}$ ) (arrow). the advantage of a single universal labeling reagent (enzyme conjugated streptavidin), instead of specific PAP complexes for each animal system.

The results obtained are almost the same identical to what had been done previously by Ramosvara [20] in a study where all infected tissue of 14 specific-pathogen-free (SPF) cats had been examined histologically for all stages of Toxoplasma life cycle. Ileum is the most common sites of infection, although in the case of eight SPF cats the entire small intestine was infected. Infection appeared to be concentrated on the epithelial cells of villi tip. In infected cells, the parasite was found between the core and border.

In this research, the positive IHC reaction was seen by the appearance of macrophage cells in both ileum and kidney. This is because T. gondii was phagocytized by macrophage cells, creating the possibility of $T$. gondii antigens to exist in the organ when IHC staining is performed using primary antibody and secondary antibody. According to Hutchison et al. [21], Cazabone et al. [22] antigen will circulate the parasite products produced at the time the parasites invade macrophages. The presence of this antigen indicating the infection is acute and still active. Antigen circulation, in principle, has the same composition and structure with soluble antigen.

T. gondii infection can generate non-specific and specific immunity. Non-specific immunity is conducted by macrophages and natural killer (NK) cells. Specific immunity is proven by the ability of $T$. gondii to induce humoral and cellular response. Cellular response against $T$. gondii infection is more dominant than humoral response. At the initial infection, macrophages infected by $T$. gondii tachyzoites produced interleukin (IL-2), tumor necrotic factor- $\alpha$, IL- $\beta$, and IL-15. Cytokine IL-12 activates NK cells to produce interferon- $\gamma$ (IFN) [23].

On further infection, when adaptive immunity is activated, tachyzoites that infect macrophages or other cells that act as antigen-presenting cells (APC) was digested by lysosomes. T. gondii tachyzoites antigens are then presented by major histocompatibility complex II molecules on the macrophages or APC membrane. The appearance of antigen is recognized and captured by receptors (Th-cell receptor [TCR]) owned by $\mathrm{T}$ helper lymphocytes (Th cells). The bond between antigen and TCR triggered Th cells to produce IL-2. T. gondii tachyzoites also triggers APC to produce IL-12. IL-12 produced by macrophages and APC working in synergy with IL-2 to cause Th cell differentiation into Th1. Th1 cells produced IFN- $\gamma$. Antigen and receptor bond activates CD8 $+\mathrm{T}$ cells to produce IFN- $\gamma$. The existence of IL- 2 produced by Th1 cells also reinforced the activation of CD8 + T cells, resulting in more production of IFN- $\gamma$. IFN- $\gamma$ produced by NK cells, Th1 or CD8 + T encourages macrophages to function as microbicides [23].

Macrophages are the predominant leukocytes beside neutrophil, eosinophil, basophil, monocyte, 
Table-1: Distribution lesions in cat organ infected by Toxoplasma.

\begin{tabular}{|c|c|c|c|c|}
\hline \multirow[t]{2}{*}{ Organ } & \multicolumn{2}{|c|}{$\begin{array}{c}\text { Domestic cat serologically Toxoplasma } \\
\text { positive }\end{array}$} & \multicolumn{2}{|c|}{ Domestic cat infected by oocyst Toxoplasma } \\
\hline & Necrotic lesions & Detection of $T$. gondii by IHC & Necrotic lesions & Detection of $\mathrm{T}$. gondii by IHC \\
\hline Ileum & + & + & + & + \\
\hline Jejunum & - & - & - & - \\
\hline Duodenum & - & - & - & \\
\hline Kidney & + & + & - & - \\
\hline Lung & - & - & - & - \\
\hline Liver & + & - & - & - \\
\hline Spleen & - & - & - & - \\
\hline
\end{tabular}

IHC=Immunohistochemistry, $T$. gondii=Toxoplasma gondii

and lymphocyte [24]. Monocyte in blood circulation will differentiate into macrophage in the tissues. Monocyte or macrophage is the most dominant to be infected by Toxoplasma then followed by neutrophil and lymphocyte. The ability of tachyzoites is to reproduce decrease when it infected the neutrophil, but it will increase again when the tachyzoites infected other cells or tissues. All types of cells in various organs, except erythrocytes, can be infected by $T$. gondii. Thus, it is assumed that the cells in the ileum were also infected, which was the reason of macrophage activity increased.

The presence occurrence of blood (Figure-3) in feces of infected cat is caused by damages on intestinal wall Bañales et al. [25] stated that tachyzoites multiply in the lamina propria of the intestine and eventually spread throughout the entire body. Tachyzoites cause tissue damage and eventually develop into bradyzoite stage after which they form tissue cysts.

Numerous positive lesions were detected in all organs characterized by necrotic lesions (Table-1; Figure-4a and b). All findings are shown in Table-1. Domestic cat serologically Toxoplasma positive, necrotics lesions were mainly observed in the ileum, kidney, and liver. While in domestic cat infected by oocyst Toxoplasma, the necrotics lesions were mainly observed in the ileum, this caused by the stage of the infection is still preliminary or it is an acute infection, thus the parasite is not spreading to all organs yet. Figure- 4 shows the necrosis of the cells of ileum and kidney of cat. The necrosis was in karyolysis category, described by the loss of nucleus in some cells.

\section{Conclusion}

The appearance of Toxoplasma antigen is successfully detected in several organs of domestic cat using IHC method with LAB-SA.

\section{Author's Contributions}

$\mathrm{MH}$ and RWN supervised the overall research work. JP, SH, RYS, BS, and DA participated in sampling, made available relevant literatures and executed the experiment and analyzed the tissue and data. All authors interpreted the data, critically revised the manuscript for important intellectual contents and approved the content.

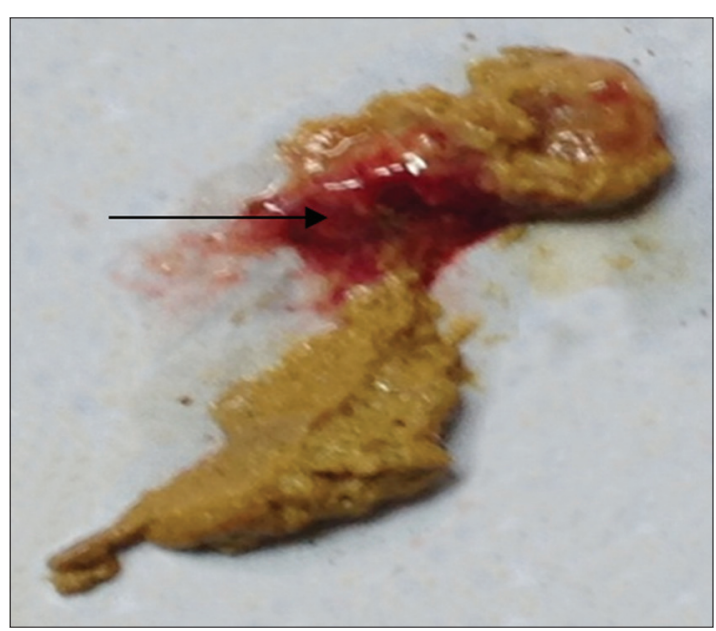

Figure-3: Blood in cat feces which infected by Toxoplasma (arrow).

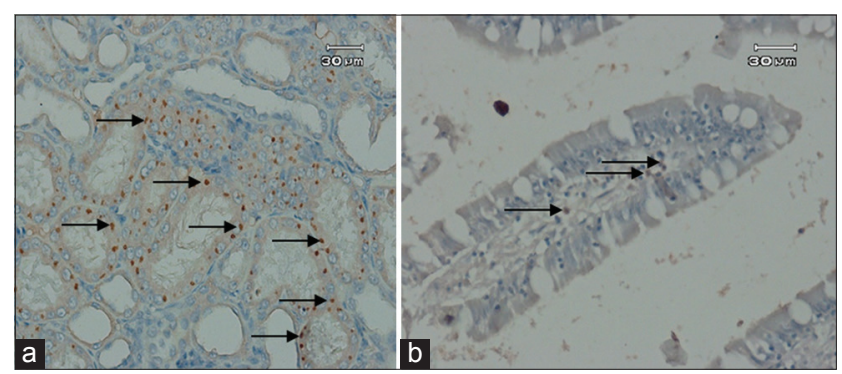

Figure-4: Toxoplasma positive immunohistochemistry staining of cat with labeled-(Strept) avidin-biotin method: (a) Necrosis is present in kidney and (b) ileum (arrow) (brown color is indicating the positive result of immunohistochemistry) (scale bar=30 $\mu \mathrm{m}$ ).

\section{Acknowledgments}

The authors would like to thank Mrs. R. R. Devita Anggraini from the Department of Clinic, Gadjah Mada University, and Mrs. Yuli Purwandari K from the Department of Pathology, Gadjah Mada University, for their support in performing IHC method. The research was funded by Directorate General of Higher Education (DIKTI), Ministry of Research, Technology, and Higher Education of Indonesia, with contract number 019/UN11.2/LT/SP3/2015.

\section{Competing Interests}

The authors declare that they have no competing interest. 


\section{References}

1. Dubey, J.P. (2010) Toxoplasmosis of Animals and Humans. $2^{\text {nd }}$ ed. CRC Press, Boca Raton, Florida. p313-314.

2. Nardoni, S., Angelici, M.C., Mugnaini, L. and Mancianti, F. (2011) Prevalence of Toxoplasma gondii infection in Myocastor coypus in a protected Italian wetland. Parasit. Vectors, 4: 240.

3. Chen, J., Xu, M.J., Zhou, D.H., Song, H.Q., Wang, C.R. and Zhu, X.Q. (2012) Canine and feline parasitic zoonoses in China. Parasit. Vectors, 5: 152-154.

4. Tian, Y.M., Dai, F.Y., Huang, S.Y., Deng, Z.H., Duan, G. and Zhou, D.H. (2012) First report of Toxoplasma gondii seroprevalence in peafowls in Yunnan Province. Southwestern China. Parasit. Vectors, 5: 205-207.

5. Scallan, E., Hoekstra, R.M., Angulo, F.J., Tauxe, R.V., Widdowson, M.A., Roy, S.L., Jones, J.L. and Griffin, P.M. (2011) Foodborne illness acquired in the United Statesmajor pathogens. Emerg. Infect. Dis., 17: 7-15.

6. Papatsiros, V.G., Athanasiou, L.V., Stougiou, D., Papadopoulos, E., Maragkakis, G.G., Katsoulos, P.D., Lefkaditis, M., Kantas, D., Tzika, E.D., Tassis, P.D. and Boutsini, S. (2016) Cross-sectional serosurvey and risk factors associated with the presence of Toxoplasma gondii antibodies in pigs in Greece. Vector. Borne. Zoonotic. Dis., 16(1): 48-53.

7. Melo, M.B., Jensen, K.D.C. and Saeij, J.P.J. (2011) Toxoplasma gondii effectors are master regulators of the inflammatory response. Trends. Parasitol., 27: 487-495.

8. Hunte, C.A. and Sible, L.D. (2012) Modulation of innate immunity by Toxoplasma gondii virulence effectors. Nat. Rev. Microbiol., 10: 766-778.

9. Dubey, J.P. (2008) The history of Toxoplasma gondii-the first 100 years. J. Eukaryot. Microbiol., 55: 467-475.

10. Zhou, P., Chen, Z., Li, H.L., Zheng, H., He, S. and Lin, R.Q. (2011). Toxoplasma gondii infection in humans in China. Parasit. Vectors, 4: 165-168.

11. Armand, B., Solhjoo, K., Kordsooli, M.S. and Davami,M.H. (2016) Toxoplasma infection in sheep from south of Iran monitored by serological and molecular methods; risk assessment to meat consumer. Vet. World, 9(9): 850-855.

12. Ahmed, A.H., Shafik, M.S., Mahmoud, E.M., Elgamry, T.S. and Ahmed, A.A. (2014) Molecular detection of Toxoplasma gondii DNA in milk and risk factors analysis of seroprevalence in pregnant women at Sharkia, Eqypt. Vet. World, 7(8): 594-600.

13. Zhang, H., Thekisoe, O.M., Aboge, G.O., Kyan, H., Yamagishi, J., Inoue, N., Nishikawa, Y., Zakimi, S. and
Xuan, X. (2009) Toxoplasma gondii: Sensitive and rapid detection of infection by loop-mediated isothermal amplification (LAMP) method. Exp. Parasitol., 122: 47-50.

14. Tonouhewa, A.B.N., Akpo, A., Adoligbe, C., Hounmanou, Y.G., Assogba, M.N., Youssao, I., Yessinou, E. and Farougou, S. (2017) Toxoplasma gondii infection in meat animals from Africa: Systematic review and meta-analyisis of sera-epidemiological studies. Vet. World, 10(10): 194-208.

15. Xiaohong, H., Xuenan, X., Haruyuki, H., Naoaki, Y., Longshan, X., Naoyoshi, S. and Ikuo, I. (2004) Rapid immunochromatographic test using recombinant SAG2 for detection of antibodies against Toxoplasma gondii in cats. J. Clin. Microbiol., 42: 351-353.

16. Greene, C.E. (2006) Infectious Diseases of the Dog and cat. $3^{\text {rd }}$ ed. W. B. Saunders Co., Philadelphia, PA. p754-775.

17. Santos, V.L.S., Williams, S., Zavala, G., Zhang, J., Cheng, S., Santos, R.L., Brown, C.C. (2009) Detection of reticuloendotheliosis virus by immunohistochemistry and in situ hybridization in experimentally infected chicken embryo fibroblast. Braz. J. Vet. Pathol., 2: 29-34.

18. Basso, W., Handke, M., Sydler, T., Borel, N., Grimm, F., Sidler, X. and Deplazes, P. (2015) Involvement of Toxoplasma gondii in reproductive disorder in Swiss pig farm. Parasitol. Int., 64(2): 157-160.

19. Bionisch, T.M.S. (2001) Immunological Staining Methods. $3^{\text {rd }}$ ed. California, USA, Carpinteria.

20. Ramosvara, J.A. (2005) Technical aspects of immunohistochemistry. Vet. Pathol., 42(4): 405-408.

21. Hutchison, W.M., Dunachie, J.F., Work, K. and Siim, J.C. (1971) The life cycle of the coccidian parasite, Toxoplasma gondii, in the domestic cat. Trans. R. Soc. Trop. Med. Hyg., 65: 380-385.

22. Cazabone, P., Bessieress, M.H. and Seguella, J.P. (1994) Kinetics study and characterization of immunoglobulin G, $\mathrm{M}, \mathrm{A}$ and $\mathrm{E}$ antibodies from mice infected with different strain of T. gondii. J. Parasitol., 80: 58-63.

23. Denkers, E.Y. and Gazzinelli, R.T. (1998) Regulation and function of T-cell mediated immunity during Toxoplasma gondii infection. Clin. Microbiol. Rev., 11: 569-588.

24. Vince, G.S. and Johnson, P.M. (2000) Leucocyte populations and cytokine regulation in human utero placental tissues. Biochem. Soc. Trans., 28: 1991-1995.

25. Bañales, P., Yamada, M., Narita, M., Shimura, K. and Nakamura, K. (2006) Immunohistochemical distribution of protozoa in experimental porcine toxoplasmosis. Jpn. Agric. Res. Q., 40: 79-83.

\section{$* * * * * * * *$}

